$$
y_{0}^{2 m}
$$


Distribuclón del ingreso e incidencia de la pobreza a lo largo del ajuste

Oscar Altimir

Nuevas orientaciones para la gestión pública

Eugenio Lahera

Industrias petroquímica y de máquinas herramientas:

estrategias empresariales

Daniel Chudnovsky, Andrés López y Fernando Porta

Productividad, crecimiento y exportaciones industriales de Brasil

Regis Bonelli

Maquila en el Caribe: la experiencia de Jamaica

Larry Willmore

Elasticidad-precio de las exportaciones agrícolas de Centroamérica

De la inflaclón crónica a la inflación moderada en el Ecuador

Luis I. Jácome Hidalgo

Nuevas estrategias de las empresas transnacionales en la Argentina

Bernardo Kosacoff y Gabriel Bezchinsky

Informalidad y pobreza en América Latina

Guillermo Rosenbluth

Crisis y alternativas en los procesos de regionalización

Sergio Boisier

Una perspectiva cultural de las propuestas de la CEPAL

Fernando Calderón, Martín Hopenhayn y Ernesto Ottone

La CEPAL y el neoliberalismo: entrevista a Fernando Fajnzylber

Orientaciones para los colaboradores de la Revista de la CEPAL

Publicaciones reclentes de la CEPAL 


\section{Industrias petroquímica y de máquinas herramientas: estrategias empresariales}

\section{Daniel Chudnovsky \\ Andrés López \\ Fernando Porta}

Investigadores del Centro de

Investigaciones para la

Transformación (CENIT),

Buenos Aires.
En Argentina, Brasil y México se han efectuado recientemente reformas estructurales que establecen inéditas condiciones de competencia. Los mayores cambios afectan a las políticas comercial e industrial y al sistema público-privado de relaciones productivas. En este contexto, las empresas manufactureras disfrutan de menores niveles de protección y asistencia estatal y tienen menos margen para estrategias de diferenciación de precios en el mercado interno. La literatura ortodoxa, y recomendaciones en boga en la región, sugieren que la mayor competencia llevaría a las empresas a incrementar sus actividades y esfuerzos tecnológicos. También se ha señalado, desde una óptica diversa, que, por el contrario, la disminución de los niveles de protección y asistencia las forzaría a desaparecer. Las investigaciones realizadas tienden a desmentir el cumplimiento inmediato de las hipótesis "eficientista" y "desindustrialista"; sugieren que el proceso es más complejo y reconocen que la historia previa de la firma y del sector también condiciona sus estrategias actuales. En México, donde el programa de reformas lleva más tiempo, las firmas se repliegan hacia productos maduros, abandonan o postergan planes de expansión o de especialización en productos nuevos y recortan significativamente las actividades tecnológicas. Sus pares argentinas y brasileñas, con reformas más recientes, han tomado en el corto plazo decisiones que parecen señalar el mismo camino. En ninguno de los tres casos se han registrado hasta el momento cierres masivos de plantas o estrategias basadas principalmente en la comercialización de productos importados. 
I

\section{Introducción}

Sendos estudios de casos realizados recientemente en Argentina, Brasil y México - Chudnovsky, López y Porta (1992), Erber y Vermulm (1992) y Unger, Saldaña, Jasso y Durand (1992) - han analizado con una metodología común el impacto de los respectivos procesos de ajuste estructural -iniciados en 1982 con la crisis de la deuda externa- sobre las estrategias empresariales en la industria petroquímica y la de máquinas herramientas. ${ }^{1}$ El propósito de este artículo es discutir y comparar los principales hallazgos de las tres investigaciones a la luz de las hipótesis que guiaron su realización.

A pesar de la relativa uniformidad del cuadro macroeconómico y de políticas públicas en los tres países durante 1980 y 1990, se esperaba que los comportamientos empresariales fuesen heterogéneos. La investigación se propuso captar los múltiples factores determinantes de la conducta microeconómica y su interacción. Se consideró que las diferentes estrategias empresariales debían explicarse no sólo por los atributos y características particulares de las firmas, sino también por el patrón estructural del sector industrial en el que operan y por la regulación macroeconómica predominante.

El estudio se concentró en un sector productor de insumos de uso difundido y en otro de bienes de capital que presentan configuraciones técnicoeconómicas y de mercado muy diversas. También es contrastante la naturaleza de la firma "típica" en uno y otro. En la industria petroquímica predominan empresas pertenecientes a grandes grupos económicos nacionales y filiales de empresas transnacionales (ET). En la industria de máquinas herramientas, en cambio, la mayor parte de las firmas son pequeñas y medianas

$\square$ Este artículo sintetiza el estudio comparativo (Chudnovsky, López y Porta, 1993) preparado como parte del proyecto "Ajuste estructural y estrategias empresariales en Argentina, Brasil y México", desarrollado en 1991 y 1992 bajo la coordinación del CENIT (Buenos Aires), y con la participación de Fabio Erber (BNDS, Río de Janeiro) y Kurt Unger (CIDE, México), y con financiamiento del International Development Research Centre (IDRC) de Canadá. Los autores agradecen especialmente la colaborración de Martina Chidiak.

${ }^{1}$ Además de la recopilación bibliográfica y el análisis de fuentes secundarias, un componente esencial de la investigación fue la realización de entrevistas a firmas productoras en estos dos sectores. $y$, aun en el caso de algunas filiales de empresas transnacionales, mantienen una estructura decisoria basada en la personalidad del dueño o sus familiares cercanos (generalmente inmigrantes europeos o sus descendientes en primera generación). La mayor capacidad financiera, de planeamiento estratégico y de cabildeo de las primeras, entre otras ventajas relativas, les permite procesar mejor las señales del marco exógeno.

La investigación analizó las estrategias empresariales desplegadas en dos períodos caracterizados por configuraciones macroeconómicas y políticas económicas muy diferentes: i) la etapa de ajuste externo y fiscal a partir de la crisis de la deuda en 1982; ii) la etapa de reformas estructurales - apertura, desregulación y privatización - iniciada en la segunda mitad de los años ochenta en México y en los años noventa en Argentina y Brasil.

En la primera etapa, los altos niveles de inflación, la crisis externa recurrente y el escaso dinamismo económico del decenio de 1980 sugerían baja inversión privada y la generalización de estrategias de sobrevivencia. El enfoque ortodoxo indicaba que, dado que se trataba de economías cerradas, no cabía esperar que las firmas hubieran innovado en tecnología o mejorado sus estándares de calidad y productividad. Sin embargo, dentro de una creciente heterogeneidad del sector manufacturero, algunas empresas ampliaron en ese período su capacidad de producción y exportación e introdujeron nuevas tecnologías.

La segunda etapa podría caracterizarse por un ambiente más competitivo que estimularía a las firmas a realizar inversiones, reactivar sus esfuerzos tecnológicos, reestructurar operaciones obsoletas, introducir nuevos productos y buscar nuevos mercados (Frischtak, Hadjimichael y Zachau, 1990). En experiencias previas de apertura, sin embargo, ellas habían adoptado predominantemente reacciones de tipo defensivo, a saber, abandono de la producción propia e importación de bienes similares, degradación productiva o tecnológica y racionalización de las estructuras empresariales (especialmente en materia de personal ocupado).

Lo reciente de los cambios de política en Argentina y Brasil dificultaba la evaluación de las estrate- 
gias privadas. En cambio, cabía suponer estrategias empresariales más definidas en el caso mexicano, dada la mayor antiguiedad de los procesos de apertura y desregulación. La repetición en Argentina y Brasil de las conductas observadas en México constituía otra hipótesis por verificar. Para ello, era necesario tomar en cuenta que los respectivos procesos de ajuste y reforma estructural, si bien tienen una matriz teóricoideológica común, se llevan a cabo en cada país de un modo particular, atendiendo no sólo a las diferentes estructuras económicas sino también a factores políticos y sociológicos.

Para desarrollar estas hipótesis se consideró inapropiado el enfoque esencialmente ahistórico y atemporal que permea la literatura ortodoxa sobre el comportamiento de la empresa. En ella se la considera una institución en la que se toman decisiones en función de los cambios en las condiciones del mercado y del acervo de capital físico disponible, con el objetivo de maximizar ganancias. En lugar de mirar la empresa como un sujeto que sólo se mueve de una posición de equilibrio a otra, en esta investigación se utiliza un enfoque dinámico apoyado en las teorías neoschumpeterianas (Dosi y otros, (eds.) 1988).

Así, las decisiones de las empresas son vistas en parte como una herencia del pasado y de las circunstancias en que tuvieron lugar. Ante el cambio de éstas, las nuevas decisiones resultan de una búsqueda caracterizada por la incertidumbre $\mathrm{y}$, a su vez, dependen del contexto específico en que la firma opera (Nelson y Winter, 1982). Las decisiones de las empresas están, por lo tanto, altamente influidas por el tiempo y el contexto histórico en que se desenvuelven, así como por la naturaleza del proceso decisorio y el tipo de organización de las empresas mismas. A lo largo del tiempo, en ellas se da un proceso de aprendizaje del oficio y se acumulan información y conocimientos técnicos y comerciales. Se promueve así la creación de un acervo intangible que -dependiendo de su calidad - orientará las decisiones frente a las nuevas circunstancias.

La especificidad de los casos nacionales analizados obligó a considerar dos hechos significativos: primero, el desnivel cuantitativo y cualitativo entre los esfuerzos tecnológicos endógenos de las empresas de estos tres países y los de las empresas originarias de algunos países desarrollados. Y segundo, el menor peso relativo de las estrategias productivas respecto de las de valorización financiera o de búsqueda de rentas o subsidios.
Expuestas así algunas premisas sobre el análisis de la empresa, hay que plantear inmediatamente que la trayectoria de ésta no podía ser comprendida sin introducir la dimensión sectorial. Las características del proceso productivo, el tipo de demanda, la velocidad del cambio tecnológico, los canales de acceso a la tecnología de frontera, la configuración de la rama a nivel mundial y nacional y la forma en que se da la competencia (vía precios o más allá de ellos) son elementos claves del entorno en el cual las empresas definen sus estrategias de largo plazo.

El tipo de regulación sectorial predominante también debía ser considerado. Muchos sectores industriales se han estructurado y desarrollado a partir de una fuerte intervención del Estado. A su vez, estos marcos regulatorios se modificaron sustancialmente en el período estudiado. El análisis de las trayectorias de las empresas remitía al examen del diseño y la aplicación de dichos instrumentos en el contexto institucional peculiar de cada uno de los países. Las estructuras sectoriales y su regulación específica influyen directamente sobre las estrategias empresariales y, a la vez, amortiguan o amplifican el impacto de las modificaciones en las variables macroeconómicas y en las políticas públicas.

En cuanto a los factores macroeconómicos, se consideró prioritario discernir los efectos de las fluctuaciones en los principales precios relativos y en los niveles de actividad económica e inversión. Asimismo, se analizó la forma en que las modificaciones más significativas a la política comercial e industrial se constituyeron en señales para las decisiones de corto y largo plazo de las empresas.

El análisis del impacto de las políticas públicas requería considerar el tejido socioestatal, el grado de certidumbre de los agentes privados sobre la sustentabilidad de una determinada configuración macroeconómica y su demora en reaccionar frente a modificaciones de ella, distinguiendo entre acciones de corto y de largo plazo. Se procuró destacar aquellas cuestiones institucionales que inciden en la interacción del mercado - sobre todo en sectores donde predominan los grandes grupos económicos- y el Estado, como articulador y presunto representante del interés público, en un período de crisis fiscal y auge de la ideología liberal.

En la sección II del artículo se comparan las actuales estrategias de las empresas y se evalúan los elementos determinantes. En la sección III se analiza la historia de las empresas y del sector en el marco de las políticas predominantes en los años ochenta, ante-

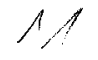

INDUSTRIAS PETROQUIMICA Y DE MAQUINAS HERRAMIENTAS: ESTRATEGIAS EMPRESARIALES • D. CHUDNOVSKY, A. LOPEZ Y F. PORTA 
cedente obligado para comprender las estrategias presentes. La evolución del cuadro macroeconómico e institucional y su efecto en las decisiones empresaria- les se examinan en la sección IV. En la sección V, por último, se analizan los principales hallazgos de la investigación a la luz de los interrogantes iniciales. ${ }^{2}$

\section{II}

\section{Las empresas frente a las reformas estructurales}

En los tres países y en ambas industrias las empresas enfrentan un escenario de menor rentabilidad, como consecuencia de la recesión internacional, las respectivas configuraciones macroeconómicas y la aplicación de reformas estructurales. En este mar$\mathrm{co}$, han tenido respuestas defensivas, suspendiendo proyectos de inversión, recortando personal y estructuras de gestión y disminuyendo gastos en actividades tecnológicas, tanto internas como extramuros.

\section{El caso mexicano}

En México el período de implantación de las reformas, de estabilización de precios y de consecución de los equilibrios macroeconómicos ha sido más largo. La consolidación de las políticas de desregulación y apertura, y fundamentalmente el acuerdo de libre comercio con Estados Unidos y Canadá, han reducido el margen de incertidumbre para las empresas. En este contexto, las estrategias de las empresas son más definidas y nítidas que las advertidas en Argentina y Brasil. $^{3}$

Las empresas mexicanas de ambos sectores tienden a consolidar y acentuar su actividad en los segmentos o líneas de producción más maduros, tratando de defender su posicionamiento oligopólico (la industria petroquímica) o sus ventajas de localización (la de máquinas herramientas). Al mismo tiempo, reducen el alcance y magnitud de sus esfuerzos tecnológicos.

Esta orientación de las estrategias empresariales

\footnotetext{
${ }^{2}$ Salvo expresa mención a otra fuente, la información y conceptos sobre cada caso nacional provienen del trabajo respectivo.

${ }^{3} \mathrm{Si}$ bien se trata de dos sectores industriales representativos de la situación que prevalece en las industrias de insumos difundidos y bienes de capital mecánicos, no deberían generalizarse estos comentarios a otras ramas de la industria manufacturera en los países estudiados. Sin embargo, investigaciones en curso en Argentina y Brasil sugieren tendencias similares en otros sectores industriales, entre ellos algunos productores de bienes de consumo.
}

estudiadas en México guarda estrecha relación con las consecuencias de casi una década de recesión y tasas de inversión bajas. Las políticas de apertura y reinserción internacional adoptadas tempranamente en este caso, si bien contribuyeron a estabilizar el escenario prospectivo de las empresas, indujeron un comportamiento predominantemente defensivo, lejano de la agresividad en materia tecnológica y de inversiones que el acicate de una mayor exposición a la competencia internacional supuestamente promovería.

¿Es éste el espejo en el que hay que mirar las perspectivas aún relativamente indefinidas de las conductas empresariales en Argentina y Brasil? El ajuste macroeconómico de los años ochenta tuvo en estos dos países, en general, características y consecuencias similares a las del caso mexicano. La orientación de las políticas de reforma estructural adoptadas recientemente y sus instrumentos principales son también relativamente semejantes. En los tres países, más allá de las diferencias de grado, las reformas representan una fuerte ruptura con las previas políticas de protección.

Por otra parte, para los países en desarrollo -y sus empresas- la posibilidad de intervenir activamente en la definición de los parámetros sectoriales de competencia es escasa o nula. La estructura productiva y de la demanda, la dinámica del progreso técnico y las formas de internacionalización de los sectores son datos exógenos y ofrecen un margen de maniobra a la evolución de las empresas argentinas, brasileñas o mexicanas.

En consecuencia, la configuración macroeconómica y de políticas públicas y los factores estructurales del sector se repiten en los tres casos. Cabe pensar que las estrategias de "atrincheramiento" en segmentos relativamente maduros y menos competidos de ambas industrias predominarán también en Brasil y Argentina. Los estudios realizados allí sugieren efectivamente el despliegue de estrategias empresariales de permanencia o de sobrevivencia, en las cuales las em- 
presas abandonan sus proyectos de inversión y aplican ajustes "racionalizadores" del empleo y las estructuras operativas.

No hay pruebas de que las empresas estén desarrollando una trayectoria de innovación tecnológica en cualquiera de las dos industrias. Las actividades innovativas de las grandes empresas locales y las filiales de empresas transnacionales en la industria petroquímica fueron muy limitadas en todo el período analizado. ${ }^{4}$ En el sector de las máquinas herramientas la posibilidad de copiar tecnología fue aprovechada en los años ochenta por un conjunto de empresas argentinas y brasileñas que habían desarrollado capacidad de diseño, las que ingresaron al desarrollo de máquinas herramientas con control numérico computarizado (MHCNC) algo a la zaga de los líderes internacionales. De todas maneras, la persistencia de mercados deprimidos y la apertura han afectado sensiblemente esta trayectoria más innovadora.

Cabe señalar que la historia previa de las ramas y principalmente de las empresas estudiadas en los tres países no es similar. Tampoco lo son los modos específicos de articulación micro-macroeconómica. Estas circunstancias otorgan algunos grados de libertad para que, aunque los contextos macroeconómicos y sectoriales sean relativamente comunes, en el futuro las trayectorias de las empresas tiendan a diferir. Por otra parte, la forma específica en que se están llevando a cabo los procesos de ajuste y reformas estructurales, así como el marco sociopolítico en que se desenvuelven, muestran rasgos particulares en cada uno de los tres casos examinados. En consecuencia, no es descartable que las empresas estudiadas en Brasil y -menos probablemente- en Argentina puedan llegar a seguir un camino diferente al transitado en México.

\section{Los factores estructurales}

El modelo de implantación y desarrollo de la industria petroquímica se estructuró sobre la base de una fuerte intervención directa del Estado en las etapas "aguas arriba", y de empresas privadas, generalmente monopólicas y monoproductoras, en cada una de las etapas sucesivas. Esta articulación público-privada re-

\footnotetext{
${ }^{4}$ Parecería que las firmas locales han hecho un mayor esfuerzo de aprendizaje tecnológico dentro del estrecho sendero definido por las características y la relativa estabilidad del paradigma tecnologico en esta industria.
}

produjo, con mayor fragmentación empresarial, la lógica de integración vertical y grandes escalas que predomina en el ámbito internacional, y permitió que esta industria participara en la distribución de la renta primaria. El nuevo marco de regulación impuesto por las reformas estructurales plantea la necesidad de cambios para mantener en los tres países tal lógica sectorial.

La menor participación estatal en la producción de hidrocarburos y productos petroquímicos y la desregulación del precio de las materias primas del sector obliga a redefinir la cadena petroquímica, para asegurar la disponibilidad de los insumos e internalizar el proceso de transferencia/disputa de la renta primaria. El desarrollo futuro de la actividad implica pasar del modelo de integración vertical dentro de la rama industrial (polo petroquímico) al esquema de integración vertical intraempresa. Los modos particulares que esta transición va adoptando en cada uno de los países remite al grado de "desincorporación" del Estado en la producción de insumos - total en Argentina, parcial en México y Brasil- y a las respectivas configuraciones empresariales.

En Argentina se ha desmantelado el aparato regulatorio vigente hasta fines de los años ochenta y el Estado se ha retirado de la producción de hidrocarburos. En Brasil el avance de las reformas es más lento y los regímenes de promoción, aunque recortados, no han sido suprimidos; por ejemplo, la empresa estatal PETROBRAS mantiene un precio subsidiado para las ventas de gasolina a la industria petroquímica. En México la empresa estatal PEMEX sigue concentrando una proporción importante de la producción petroquímica, si bien comenz 6 a retirarse de actividades "aguas abajo" en la cadena de producción. El Estado mexicano retiene el carácter de promotor del desarrollo de la industria petroquímica en tanto mantiene cierto nivel de subsidio en la venta de materias primas y productos intermedios. De todos modos, en los tres países se ha elevado el precio de las materias primas petroquímicas. Al mismo tiempo, los menores niveles de protección han tendido a alinear los precios internos de los productos petroquímicos finales con los internacionales.

Las empresas han respondido frente al escenario de menor rentabilidad con acciones de carácter defensivo, abandonando planes de inversión y reduciendo personal. Ha seguido recorriendo una trayectoria "natural" de optimización de procesos, pero basándose mucho más en el conocimiento adquirido en la operación de las plantas que en actividades sistemáticas de 
investigación y desarrollo. En Brasil y México, probablemente por el mayor tamaño relativo del mercado interno, el interés de las empresas por desarrollar nuevas aplicaciones para sus productos parece mayor que en Argentina pero, al mismo tiempo, se han desactivado los proyectos incipientes de producción de especialidades.

En tanto, algunas empresas pertenecientes a grandes grupos económicos han comenzado a definir estrategias de más largo plazo que incluyen operaciones de integración vertical, posibilitadas fundamentalmente por los respectivos procesos de privatización. Estos movimientos tienden a ser más "hacia atrás" en Argentina y Brasil y "hacia adelante" en México; la diferencia se explica por las características específicas de los respectivos marcos regulatorios nacionales.

Queda claro que en tanto no aparezcan perspectivas de una nueva etapa de crecimiento acelerado del sector en alguno de los tres países, la redefinición de la estructura técnico-empresarial de la rama converge hacia una mayor concentración del capital y de la oferta, a favor de algunos productores privados ya instalados. La mayor o menor capacidad de participar más activamente de este proceso depende estrechamente de los flujos de fondos del conglomerado, del dinamismo relativo del submercado en que opera y de sus posibilidades de acceso a los proveedores de tecnología. En el caso de México y Argentina estos nuevos "ganadores" parecen estar más definidos que en Brasil, donde el proceso de reformas está menos avanzado y el entramado de relaciones empresariales del modelo anterior aparece más rígido, dificultando la concreción de las operaciones de integración vertical.

La exposición del caso de la industria petroquímica muestra cómo operan los factores estructurales del sector (lógica internacional y regulación nacional) sobre las posibles alternativas de estrategias privadas. Las características y la relativa estabilidad del paradigma tecnológico sectorial definían un estrecho margen de acción ante las opciones tecnológicas. Por un lado, el bajo nivel posible de gastos en investigación y desarrollo de las firmas latinoamericanas en comparación con el de las que lideran el ámbito internacional (dada la envergadura relativa de las empresas) excluía innovaciones mayores en procesos y productos. Por otro, el desarrollo de proyectos en productos maduros y de tecnología relativamente difundida obligaba a que, para tener resultados comerciales satisfactorios, las empresas hicieran un apren- dizaje de operación que incluía actividades tecnológicas rutinarias.

Asimismo, mientras la regulación nacional suplantaba la lógica de la integración vertical intraempresa por la articulación público-privada dentro de la rama industrial, las producciones locales gozaban de un margen de protección muy elevado, con la consecuente limitación de la competencia en el mercado interno. La estrechez del sendero tecnológico y los marcos regulatorios de amplio alcance no daban espacio para una gran diferenciación de las estrategias empresariales.

El cambio en el marco regulatorio ha recreado las estrategias de las empresas, aun cuando los factores tecnológicos no se hayan modificado significativamente. Sin embargo, no se introducen ahora necesariamente diferencias mayores en las decisiones en curso. En particular, siguen ausentes las estrategias de mejoramiento tecnológico-productivo. Con todo, para permanecer en el negocio, las empresas deben tratar de avanzar activamente hacia una mayor integración vertical. El éxito relativo (frente a otros productores) depende fundamentalmente de la capacidad empresarial para competir en el proceso de privatizaciones.

El sendero tecnológico posible para las empresas instaladas tiende a cerrarse aún más. De un lado, la mayor competencia en los mercados internos eleva el piso de actividades tecnológicas necesarias para garantizar su permanencia. De otro, el recorte de gastos en este ámbito limita la capacitación tecnológica y las posibilidades de introducir mejoras en procesos y productos. Aun cuando probablemente no se afecte la sobrevivencia de las empresas a corto plazo, a largo plazo disminuye la capacidad de selección y absorción de tecnologías para eventuales nuevas inversiones. Además, en los casos mexicano y brasileño se ha comprobado que las condiciones de acceso a tecnología externa han empeorado desde fines de los años ochenta.

En la industria de las máquinas herramientas los determinantes estructurales son otros. Esto llevó a que, en el período en estudio, sus estrategias empresariales fuesen más diferenciadas que en la industria petroquímica. Las reformas estructurales en curso parecen amenazar en mayor medida el sostenimiento de aquellas estrategias tecnológico-productivas más osadas. Desde el punto de vista de la configuración sectorial, los efectos sobre la industria de las máquinas herramientas parecen apuntar a una apreciable degradación productiva y a 
un aumento de la brecha tecnológica respecto de países desarrollados.

En los años ochenta, en los países estudiados esta industria estuvo afectada por dos tendencias diferentes. Por un lado, se generalizó la difusión de un nuevo paradigma productivo - basado en la incorporación de máquinas herramientas con control numérico computarizado- que renovó tanto los productos como los procesos productivos de la rama. Por otro, la recesión, que tuvo un particular impacto negativo en el proceso de inversión, debilitó en especial la demanda dirigida al sector. La combinación de estos dos factores generó un cuadro complejo en el que, mientras el impulso tecnológico orientaba hacia estrategias ofensivas, la contracción del mercado alentaba acciones defensivas.

A diferencia de lo sucedido en la industria petroquímica, ni en México ni en Argentina hubo un marco regulatorio específico que modificara las señales depresivas de la situación macroeconómica, aunque las empresas argentinas se beneficiaron del acceso preferencial al mercado brasileño - de gran crecimiento entre 1985 y 1989 - a partir de la firma del acuerdo binacional de integración en bienes de capital. En tanto, sin que hubiera un régimen particular de promoción como el vigente para la petroquímica, las empresas brasileñas accedieron a financiamiento preferencial y estuvieron relativamente más protegidas frente a las importaciones.

En otros términos, lo que más influyó en la configuración de los factores estructurales en la industria de las máquinas herramientas fueron las políticas generales de ajuste macroeconómico y la acelerada mutación en el patrón de progreso técnico. En los años ochenta se inició un proceso de reestructuración de la rama que implicó el agotamiento de un incipiente programa estatal de implantación de la industria en México, así como la desaparición de un número importante de empresas en Argentina y -en menor medida- en Brasil. En estos dos países algunas empresas accedieron, con suerte diversa, al nuevo paradigma tecnológico. Es evidente que la mayor flexibilidad del proceso productivo en esta rama, la posibilidad de copia y la ausencia de un marco regulatorio específico (tres diferencias notables respecto de la petroquímica) permitieron el despliegue de estrategias empresariales más diferenciadas.

El liderazgo en Argentina y Brasil fue retenido por aquellas empresas que incorporaron a su combinación de productos una proporción considerable de máquinas herramientas con control numérico compu- tarizado. Todas ellas habían acumulado considerable experiencia en ingeniería de productos y de procesos. Excepto en el caso de una empresa argentina, muy debilitada en su evolución posterior, todas accedieron al nuevo paradigma a través de la vinculación (patrimonial o vía licencias) con empresas líderes a escala internacional. El mayor desarrollo relativo de las empresas brasileñas parece explicarse por un ingreso más temprano a la producción en escala comercial de MHCNC, su mayor tamaño relativo, su condición de filiales de empresas transnacionales (en tres de los cuatro casos detectados), una configuración macroeconómica comparativamente menos recesiva, una fuerte protección frente a las importaciones y la permanencia de algunos mecanismos promocionales de financiamiento de las ventas.

Una integración vertical y una diversificación de productos superiores a los estándares internacionales - profundizadas en las condiciones de incertidumbre e inestabilidad de los años ochenta - venían ya restringiendo la evolución de estas empresas dentro del nuevo paradigma. Aunque en la actualidad las empresas líderes en Brasil están aumentando fuertemente sus exportaciones (su competitividad tiende a asentarse en los equipos convencionales y en un mejor acceso a redes de comercialización por su carácter de extranjeras) las condiciones recesivas en el mercado interno complican el sostenimiento de estas estrategias de liderazgo. Por otra parte, el acceso más barato a componentes importados es, en cambio, un factor potencial favorable y las empresas brasileñas alegan no sentirse amenazadas por la competencia de MHCNC importadas (sujetas a un arancel todavía elevado). Sin embargo, en la actual coyuntura, las empresas de este tramo han disminuido considerablemente sus actividades tecnológicas internas y cancelado los proyectos de inversión.

La evolución de las empresas argentinas se ha tornado particularmente difícil tanto en los mercados regionales como en el interno, ya que a la modificación abrupta en las condiciones de competencia se suma el rezago del tipo de cambio y la falta de financiamiento para los usuarios internos y extranjeros, neutralizando las ventajas de la localización y la experiencia exportadora. En esas condiciones se han suspendido los proyectos de expansión, se ha reducido fuertemente la producción y las exportaciones, ha disminuido considerablemente el personal empleado, y una de las empresas líderes pasó a ser controlada por una gran empresa italiana.

La acumulación de factores de inercia y la in- 
certidumbre sobre las posibilidades competitivas en el nuevo contexto debilitan las estrategias de liderazgo y, con ello, la posibilidad del segmento más avanzado de la industria de máquinas herramientas en estos países de, por lo menos, no ahondar la brecha que la separa de las empresas líderes en el ámbito internacional. Por otra parte, se refuerza la necesidad de asociarse con empresas extranjeras, lo que cambiará significativamente el mapa empresarial tradicional del sector. Las estrategias intermedias adoptadas por algunas empresas en Argen- tina y Brasil, que implicaban un mejoramiento paulatino de la tecnología de productos y procesos e intentos más tímidos de ingreso a la producción de MHCNC, aparecen también fuertemente castigadas. El manejo del oficio aprendido en largos años de actividad, la existencia de un amplio mercado remanente para máquinas convencionales y la importancia que mantiene la relación directa con usuarios sumamente atomizados explican la generalización de estrategias de sobrevivencia, relativamente pasivas, en los tres casos.

\section{III}

\section{La historia previa de las empresas y los sectores}

Para comprender la lógica de los cambios recientes en las estrategias microeconómicas y en la configuración industrial, es preciso considerar la historia previa de las empresas y de los respectivos sectores y la evolución específica de la relación micro/macro en cada caso. Estos aspectos -que imponen restricciones y brindan el marco de posibilidades para las actividades actuales de las empresas- se analizan seguidamente.

\section{La industria petroquímica}

Las tasas de crecimiento de la producción y el consumo aparente de productos petroquímicos en Argentina, Brasil y México fueron muy superiores a las del producto interno bruto en 1970 y 1980 (cuadro 1), lo que indica un importante proceso de sustitución de materiales tradicionales por productos petroquímicos.

Argentina, Brasil y México: Tasas de crecimiento anuales del PIB y de la producción y el consumo aparente de productos petroquímicos a

(Porcentajes)

\begin{tabular}{|c|c|c|c|c|c|c|c|c|}
\hline & \multicolumn{2}{|c|}{ PIB } & \multicolumn{2}{|c|}{$\begin{array}{l}\text { Producción } \\
\text { petroquímica }\end{array}$} & \multicolumn{2}{|c|}{$\begin{array}{c}\text { Consumo } \\
\text { petroquímico }\end{array}$} & \multicolumn{2}{|c|}{$\begin{array}{l}\text { Consumo de } \\
\text { productos } \\
\text { petroquímicos } \\
\text { finales }\end{array}$} \\
\hline & $\begin{array}{l}1970- \\
1980\end{array}$ & $\begin{array}{l}1980- \\
1990\end{array}$ & $\begin{array}{l}1970- \\
1980\end{array}$ & $\begin{array}{l}1980- \\
1990\end{array}$ & $\begin{array}{l}1970- \\
1980\end{array}$ & $\begin{array}{l}1980- \\
1990\end{array}$ & $\begin{array}{l}1970- \\
1980\end{array}$ & $\begin{array}{l}1980- \\
1990\end{array}$ \\
\hline Argentina & 2.6 & -1.1 & 6.4 & 8.6 & 4.3 & 7.0 & 5.6 & 2.2 \\
\hline Brasil & 8.6 & $1.5^{b}$ & 27.3 & $4.9^{b}$ & 22.5 & $3.7^{b}$ & 15.8 & $3.0^{\mathrm{b}}$ \\
\hline México & 6.6 & 1.6 & 12.7 & 12.0 & 12.3 & 8.8 & 11.3 & 5.0 \\
\hline
\end{tabular}

Fuente: Elaboración propia sobre datos de la APLA (1988 y 1991), el BID (1991), Clemente de Oliveira (1990), Chudnovsky, López y Porta (1992), Erber y Vermulm (1992), Gutiérrez (1991) y Unger, Saldaña, Jasso y Durand (1992).

a Para efectuar esta comparación se han homogeneizado los datos de los tres países, definiendo un universo de productos petroquímicos. Este universo incluye los productos básicos e intermedios, resinas termoplásticas y termorrígidas, elastómeros y solventes. Excluye en cambio las fibras sintéticas, los fertilizantes y las especialidades químicas.

b $1980-1989$. 
Como consecuencia de la mayor envergadura de sus mercados internos y del mantenimiento de un fuerte ritmo de crecimiento económico, especialmente en los años setenta, las industrias petroquímicas brasileña y mexicana han alcanzado un tamaño muy superior a la argentina (cuadro 2). ${ }^{5}$

\section{a) Características estructurales}

La industria petroquímica se caracteriza por el predominio de procesos de producción continuos, elevadas relaciones capital-producto y capital-trabajo e importantes efectos de escala. Estos rasgos definen patrones de oferta altamente concentrados en los países productores, fenómeno que se acentúa en el caso de los países en desarrollo.

En Argentina, Brasil y México los tamaños medios de las plantas han crecido junto con el proceso de industrialización, a partir de un comienzo en el cual se instalaban plantas de pequeña escala pensadas para el mercado interno. Las plantas inauguradas en

CUADRO 2

Argentina, Brasil y México: Producción, comercio exterior y consumo aparente de productos petroquímicos, 1990

(Miles de toneladas)

\begin{tabular}{lcccc}
\hline & Producción & Importación & Exportación & Consumo aparente \\
\hline Argentina & 2299.4 & 289.8 & 576.3 & 2012.9 \\
Brasil a $^{\text {México }}$ & 10138.5 & 277.9 & 1107.3 & 9309.1 \\
\hline
\end{tabular}

Fuente: Elaboración propia sobre datos de la APLA (1988 y 1991), BID (1991), Clemente de Oliveira (1990), Chudnovsky, López y Porta (1992), Erber y Vermulm (1992), Gutiérrez (1991) y Unger, Saldaña, Jasso y Durand (1992).

a 1989.

Brasil y México en los años setenta son ya de escala internacionalmente eficiente. En el caso argentino esta transición se produjo de manera más irregular y finalizó sólo en los años ochenta. Actualmente en los tres países las escalas se están alineando con los niveles internacionales óptimos.

En los tres se avanzó en la construcción de complejos o polos petroquímicos integrados, en los cuales el Estado generalmente asumía el control de las producciones de materias primas; estos polos funcionaban como sustitutos de la elevada integración vertical de las grandes transnacionales petroquímicas en los países desarrollados. ${ }^{6}$ En Brasil esta tendencia se impuso más extensamente y se construyeron tres grandes polos, con una gran densidad de flujos

5 Si se consideraran también las producciones en fibras sintéticas y fertilizantes, las diferencias a favor de Brasil y México serían bastante mayores.

6 La importancia de las economías de escala, la presencia de coproductos en los procesos más usados y los altos costos y riesgos de transporte de algunos productos justifican un alto grado de integración técnica en la industria petroquímica. En los países desarrollados se observa además una fuerte integración vertical en las principales empresas productoras, lo cual permite obtener importantes ventajas competitivas (precios de transferencia, seguridad de abastecimiento y otras). insumo-producto y un nivel de autoabastecimiento casi completo.

En Argentina se impulsó a fines de los años sesenta la construcción de dos grandes polos petroquímicos integrados, pero por desistimientos o demoras de los inversores privados surgieron desequilibrios en los flujos de insumo-producto que aún no han sido resueltos y que han dado lugar a importantes corrientes de exportación e importación de productos básicos (cuadro 3). En consecuencia, la estructura productiva exhibe un insuficiente grado de integración; buena parte del árbol petroquímico permanece ausente, en especial en el caso de los intermediarios para las fibras.

México presenta características intermedias, con menor hincapié en la construcción de polos integrados que Brasil (las plantas más modernas de PEMEX son las que más se acercan al paradigma de los polos). Al igual que en Argentina, exhibe algunos desequilibrios en la cadena insumo-producto sectorial, lo cual se refleja en coeficientes de importación bastante elevados (aunque disminuyeron a lo largo de los años ochenta). Buena parte de la responsabilidad por las desarticulaciones en las cadenas de insumo-producto se debe a la suspensión de inversiones 
CUADRO 3

Argentina, Brasil y México: Coeficientes de exportación e importación de productos petroquímicos en volúmenes físicos, 1980 y 1990

(Porcentajes)

\begin{tabular}{lccccc}
\hline & \multicolumn{2}{c}{1980} & & \multicolumn{2}{c}{1990} \\
\cline { 2 - 5 } & $\begin{array}{l}\text { Exportaciones/ } \\
\text { producción }\end{array}$ & $\begin{array}{c}\text { Importaciones/ } \\
\text { consumo aparente }\end{array}$ & $\begin{array}{c}\text { Exportaciones/ } \\
\text { producción }\end{array}$ & $\begin{array}{c}\text { Importaciones/ } \\
\text { consumo aparente }\end{array}$ \\
\hline Argentina & 25.8 & 26.5 & 25.1 & 14.4 \\
Brasil & 3.4 & 6.2 & $10.9^{\mathrm{a}}$ & $3.0^{\mathrm{a}}$ \\
México & 6.0 & 26.7 & 14.7 & 11.2 \\
\hline
\end{tabular}

Fuente: Elaboración propia sobre datos de la APLA (1988 y 1991), BID (1991), Clemente de Oliveira (1990), Chudnovsky, López y Porta (1992), Erber y Vermulm (1992), Gutiérrez (1991) y Unger, Saldaña, Jasso y Durand (1992).

a Estos datos se refieren a 1989.

que debía realizar PEMEX en ese decenio en segmentos de productos básicos e intermedios.

Si bien durante los años ochenta las exportaciones fueron el factor más dinámico de demanda en los tres países, el crecimiento no estuvo liderado por las exportaciones. La mayoría de las plantas fueron planeadas con el objetivo de sustituir importaciones y la exportación fue una respuesta a una demanda local inferior a la prevista. Sin ella, las ventajas de costos y productividad derivadas de la construcción de plantas de escala internacional se hubieran visto reducidas debido a los altos márgenes de capacidad ociosa. En consecuencia, además de cumplir su papel anticíclico, las exportaciones han estado asociadas con la desaceleración del crecimiento interno en los tres países durante los años ochenta. ${ }^{7}$ De todos modos las empresas consultadas, teniendo en cuenta la experiencia de esa década, prevén un flujo permanente de exportaciones en sus estrategias con el objetivo de mantener cierta diversificación de los mercados.

b) Marco regulatorio y tipo de empresas

En los decenios de 1970 y 1980 la industria petroquímica recibió una intensa inversión privada y estatal en los tres países; en los años ochenta, esto contrastó notablemente con la caída en la tasa de inversión global. Un elemento que explica esta dinámica es el retraso entre el momento en que se tomaron las decisiones de inversión y el momento de apertura de las

7 En Argentina, donde la desaceleración del crecimiento fue más marcada, se observa el mayor coeficiente de exportaciones de la industria petroquímica (cuadro 3 ). plantas. Otro factor clave es la presencia de estímulos estatales generosos.

Los costos de inversión en dicha industria son elevados y los plazos de maduración de los proyectos bastante largos. En los países en desarrollo esta situación tiende a agravarse debido a tiempos de construcción más prolongados, deficiencias en la infraestructura y mayores costos de la maquinaria y equipos.

La necesidad de compensar estas desventajas, que se suman a las mayores dificultades en el acceso al crédito, ha llevado a que en los países en desarrollo sea habitual el uso de instrumentos de promoción estatal a la formación de capital, como ha sucedido en los tres casos estudiados. Parece legítimo afirmar que sin los instrumentos de promoción sectorial no se hubiera hecho sino una pequeña parte de las inversiones efectivamente concretadas en los tres países.

Estos regímenes parecen haber sido más generosos (y con un margen considerable de redundancia) en Argentina y Brasil, donde a los créditos preferenciales -que también existieron en el caso mexicano- se le agregaron políticas de promoción fiscal muy atractivas, que hicieron que el capital efectivamente invertido por las empresas privadas fuera apenas una parte minoritaria de la inversión total efectuada. El objetivo de estos estímulos fue la construcción de plantas destinadas a sustituir importaciones. El único mecanismo de quid pro quo en las políticas públicas fue el requisito de que las plantas alcanzaran ciertas escalas mínimas y, en el caso brasileño, las exigencias de índices mínimos de provisión nacional de equipos y tecnología para las plantas por construir, 
así como de apertura del paquete tecnológico por parte del socio extranjero.

Dada la importancia de los hidrocarburos en la estructura de costos sectorial, en los tres países existieron regímenes de precios preferenciales para su uso en la petroquímica, que tendían a premiar la transformación industrial de aquéllos, transfiriendo a los productores petroquímicos las rentas generadas en la extracción y producción de combustibles. En Brasil, la contrapartida de la provisión de materias primas a precios subsidiados fue la aplicación de mecanismos de control de precios que regulaban los márgenes de ganancia de los productores, consiguiendo que el efecto de los subsidios se transfiriera a los usuarios y que los precios locales no fueran demasiado superiores a los internacionales.

En Argentina, si bien también se aplicaron instrumentos de control de precios, las empresas de propiedad estatal (total o mayoritaria) productoras de bienes primarios no transfirieron hacia adelante los beneficios percibidos en el precio de sus insumos, lo cual llevó a que, operando con márgenes similares a los de las empresas brasileñas, las productoras de bienes finales tuvieran precios muy superiores a los internacionales, aprovechando la vigencia de mecanismos de protección. En México también existieron regímenes de subsidios a las materias primas usadas por el sector privado (vinculados a metas de exportación y empleo), sin que - salvo excepciones- se lograra que los precios internos de los productos finales se alinearan con los internacionales.

Otro factor relevante ha sido la existencia de regímenes de protección arancelaria y no arancelaria. La banda de protección fue aprovechada más plenamente en los casos de Argentina y México, mientras que en Brasil parece haber tenido cierto grado de redundancia (por la simultánea existencia de controles de precios). La posibilidad de discriminar en los precios entre el mercado local y el externo resultó una fuente muy importante de subsidios implícitos a las exportaciones en Argentina y México. En Brasil, en cambio, tuvieron más influjo los mecanismos de promoción explícitos. De todos modos, en los tres países el gran dinamismo de las exportaciones en los años ochenta se explica, fundamentalmente, por la recesión interna y los altos precios internacionales que se dieron en la segunda mitad de esa década.

En Brasil es donde parece haberse registrado mayor coherencia y coordinación entre los distintos instrumentos de política estatal para el sector. El Estado brasileño no sólo contribuyó a crear la oferta y la demanda simultáneamente y estimuló el surgimiento del empresariado nacional (lo cual también ocurrió en Argentina y México), sino que además, a través del Consejo de Desarrollo Industrial, diseñó una política para estructurar el sector, en el marco de una estrategia global de industrialización.

En los tres países las empresas estatales de hidrocarburos han avanzado, por sí mismas o a través de filiales, en la industria petroquímica. Las formas de esta intervención han sido diferentes. PEMEX concentró la producción de la mayor parte de la cadena petroquímica, incluidos productos intermedios y finales, y transfirió ingresos bajo la forma de precios subsidiados. En Brasil, PETROQUISA (subsidiaria de PETROBRAS) participó también en varios segmentos de la cadena, generalmente en asociación con empresas privadas, aunque no parece haber actuado con una estrategia de grupo. Las proveedoras estatales de hidrocarburos en Argentina (YPF y Gas del Estado) participaron en la construcción de las dos grandes centrales de productos básicos, pero la planificación sectorial parece haber correspondido a la Dirección General de Fabricaciones Militares.

Lo más interesante en este análisis comparativo es que, a diferencia de Brasil y México, en Argentina las empresas petrolero-gasíferas estatales avanzaron hacia la industria petroquímica de manera formal pero no efectiva, y operaron con la lógica de la rentabilidad privada, no transfiriendo los subsidios que recibían en la materia prima.

Las empresas transnacionales desempeñaron un papel decisivo en el surgimiento y desarrollo de la industria petroquímica en los países en desarrollo: en una primera etapa, a través de inversiones directas para abastecer mercados internos protegidos, y a partir de los años setenta, mediante coinversiones, licencias y contratos llave en mano que contemplaban exportaciones.

En Argentina la presencia de empresas transnacionales es menos extendida que en los otros dos países, a pesar de haber predominado en los inicios de la actividad. Si bien la inestabilidad económica, las políticas restrictivas aplicadas a comienzos de los años setenta y algún caso de decisión global de abandonar la industria petroquímica influyeron para su retiro relativo, su menor presencia deriva de que -en contraste con lo sucedido en Brasil y México- no ha sido relevante su participación como socios tecnológicos de las empresas locales, tal vez por tratarse de volúmenes de negocios relativamente poco significativos. De todas maneras, han sido activas licenciantes de tecnología. 
En los tres países hay una presencia muy importante -y creciente a lo largo del período analizadode grandes grupos de capital local; es también una característica compartida el hecho de que se trate de conglomerados que tienen un grado de diversificación bastante alto, extendiéndose fuera de la petroquímica no sólo hacia otros sectores manufactureros (vinculados o no con esta industria), sino también a las finanzas, la construcción, etc. ${ }^{8} \mathrm{El}$ tamaño y grado de integración de estos grupos es muy reducido en relación con el de las grandes empresas transnacionales químico-petroquímicas, tanto por las limitaciones institucionales para avanzar hacia la producción de bienes primarios o hidrocarburos como por las dimensiones reducidas de los mercados locales.

Los grupos mexicanos aparecen como los relativamente más concentrados en la petroquímica - principalmente en productos finales y en sus manufacturas, en virtud de la extendida reserva de mercado de PEMEX - y con estrategias empresariales más definidas. En los argentinos, en cambio, la facturación por esta actividad tiende a ser menos relevante dentro del conglomerado y, en algunos casos, no parece haber una estrategia clara para el sector. Las estrategias grupales en el caso brasileño aparecen bloqueadas por la gran fragmentación de la propiedad accionaria derivada del modelo tripartito de organización. ${ }^{9}$

\section{c) Las actividades tecnológicas}

Es posible hablar de límites estructurales - tanto inferiores como superiores- a las estrategias tecnológicas que pueden seguirse en este sector en los países en desarrollo. El piso estaría dado por aquellas actividades - fundamentalmente la optimización de procesos y el adecuado manejo de las plantas- que resultan imprescindibles para operar de manera competitiva. El techo dependería de los recursos que las empresas están en condiciones de destinar a actividades de investigación y desarrollo. El umbral de gastos de este rubro para generar innovaciones mayores en procesos y productos ha estado fuera del alcance de las empresas locales. Las transnacionales, por su parte, no han

\footnotetext{
${ }^{8}$ Estos grupos locales ingresan a la industria petroquímica, especialmente en Argentina y Brasil, casi sin experiencia previa, impulsados por las políticas estatales de promoción. Con el desarrollo de esta industria, han logrado adquirir capacidades empresariales propias a través de su experiencia en el manejo de empresas.

${ }^{9}$ El Estado participa con una parte mayoritaria de la inversión y el abastecimiento de la materia prima, el sector privado local con la parte restante de la inversión y el manejo comercial y administrativo de la firma, y la empresa extranjera como socio tecnológico.
}

asignado ese tipo de actividades a sus filiales en estos países.

Esta circunstancia ha desembocado en una relativa homogeneidad de las estrategias tecnológicas en las empresas estudiadas en los tres países. El tipo de actividades tecnológicas emprendidas varía en función del producto. En los segmentos "aguas arriba" han predominado la optimización de procesos y el ahorro de energía, mientras que "aguas abajo" se han desarrollado más actividades en tecnología de productos y asistencia técnica a los clientes. Ha sido una trayectoria "natural", en la que estos esfuerzos han resultado necesarios para la actuación de las empresas en los mercados, y se han constituido en el piso del sendero tecnológico mencionado. Las empresas más agresivas o con mayor capacidad de destinar recursos a investigación y desarrollo se plantearon objetivos más ambiciosos, como lo de modificar la tecnología de procesos con ingeniería básica propia (instalando plantas piloto), desarrollar nuevos catalizadores o mejorar los existentes, y desarrollar nuevas variedades o calidades de los productos que fabrican. ${ }^{10}$

Las empresas locales efectuaron internamente más actividades tecnológicas que las extranjeras (especialmente aquellas que carecen de socio tecnológico o lo han perdido) $\mathrm{y}$, al menos en el caso argentino, tienen mayor participación en convenios con instituciones oficiales. En Brasil, las relaciones tecnológicas extramuros fueron limitadas; las empresas que más recurrieron a ellas se ubican en el grupo de las más agresivas en materia de avance tecnológico. En México los centros de investigación estatales están muy desprestigiados por su carácter burocrático.

El pequeño tamaño de la mayoría de las empresas estudiadas causa una dispersión de esfuerzos en actividades de investigación y desarrollo. Las empresas brasileñas parecen haber alcanzado un mayor grado relativo de autonomía tecnológica y adquirido un importante acervo de conocimientos que garantiza la operación eficiente y el correcto mantenimiento de las plantas existentes. Asimismo, la industria petroquímica brasileña ha comenzado a desarrollar y vender su propia tecnología en algunos campos. Las empresas argentinas son las que menos recursos dedican, en promedio, a actividades de investigación y desarrollo, siendo consecuentemente menor el techo de las trayectorias tecnológicas observadas; las empresas esta-

\footnotetext{
${ }^{10}$ Las exportaciones en crecimiento de los años ochenta no parecen haber estimulado mayores esfuerzos tecnológicos en ninguno de los tres casos estudiados.
} 
tales y algunas empresas privadas de tamaño pequeño aparecen como las más dinámicas en actividades tecnológicas. Las empresas mexicanas han apuntado a mejorar la eficiencia de los procesos más que a desarrollar productos nuevos; algunas de ellas, las de mayor tamaño y mayor gasto en investigación y desarrollo, han puesto en marcha proyectos propios para avanzar en áreas tecnológicamente complejas, como las especialidades.

La asimilación efectiva de tecnología importada - procesos y principios básicos- ha sido limitada. El aprendizaje se centró en la ingeniería de detalle (menos desarrollada en Argentina), el montaje y la operación. El mayor avance relativo parece haberse dado en Brasil. Las empresas brasileñas encararon proyectos de aumento de capacidad con ingeniería propia, redujeron las cláusulas restrictivas y avanzaron en "desempaquetar" contratos de transferencia, y lograron mejoras en capacitación del personal, participación en el diseño de las plantas y comprensión de los principios básicos de los procesos. La política estatal brasileña de atención al desarrollo de capacidades tecnológicas locales, con créditos para investigación y desarrollo, prohibición de cláusulas restrictivas en los contratos de transferencia e impulso a posturas negociadoras agresivas, entre otras medidas, influyó en estos resultados.

En Argentina y México, en cambio, las políticas sectoriales de capacitación tecnológica no han sido significativas. Paradójicamente, más como resultado de un hecho aislado, en Argentina aparece un caso exitoso de vinculación de instituciones de investigación oficiales con algunas empresas del sector, para la capacitación de personal técnico y profesional y la provisión de servicios y asistencia técnica en diversas áreas. Las empresas argentinas se han involucrado menos que sus pares brasileñas en "desempaquetar" los contratos tecnológicos, siendo más habitual la compra de plantas llave en mano, aun en empresas que ya tienen experiencia operativa de varios años en el sector. Es probable que la ausencia de una legislación estatal que exija un mayor contenido tecnológico local en los proyectos petroquímicos explique buena parte de las diferencias que se observan en el caso argentino.

\section{La industria de máquinas herramientas}

El principal factor que impulsó la producción de máquinas herramientas en Argentina y Brasil durante décadas —en una industria desarrollada por inmi- grantes - fue el alto nivel de protección frente a las importaciones en un mercado interno en expansión. En el caso argentino, sin embargo, la apertura importadora de 1978-1981 provocó el cierre de numerosas plantas. Si bien la protección fue restablecida en 1982, el financiamiento concesional negociado posteriormente con España e Italia para la provisión de equipamiento perforó su eficacia. Tal vez el acuerdo de integración con Brasil en bienes de capital haya sido la única excepción a la regla dentro del reducido marco de incentivos que tuvo la rama en Argentina. En Brasil, por su parte, tendió a generarse de hecho una reserva de mercado, por la extensión del criterio de similaridad. Adicionalmente, las empresas instaladas en Brasil, a diferencia de las argentinas, fueron favorecidas con amplios regímenes y mecanismos de financiación de sus ventas, por lo menos hasta finales de la década de 1980.

La historia del sector en México es sustancialmente distinta, al parecer por sus menores niveles de protección históricos y la cercanía de los proveedores norteamericanos. El gobierno buscó impulsar la fabricación de máquinas herramientas mediante la participación directa en varias iniciativas entre 1975 y 1978. La política gubernamental incluía financiamiento $\mathrm{y}$ protección arancelaria, así como un trato preferencial en las compras estatales. Por diversas razones, las empresas paraestatales no tuvieron éxito. En el marco de las condiciones macroeconómicas predominantes desde 1982 y de la apertura comercial desde mediados de los años ochenta, pocas empresas resistieron la presión de las importaciones, sobre todo de máquinas herramientas usadas.

Brasil es el productor de máquinas herramientas más grande de América Latina. La producción brasileña creció sostenidamente hasta 1980 y se desplomó en la recesión de 1981-1983. Luego de una progresiva reactivación que llevó a superar en 1988 el volumen máximo alcanzado a principios de la década, declinó nuevamente: las ventas en 1990 fueron de 314 millones de dólares, contra 628 millones en 1988. En Argentina el máximo nivel de producción se registró en 1978; posteriormente se inició un ciclo recesivo hasta 1984 y una etapa de reactivación hasta 1988, año en el que el valor de la producción fue de 48 millones de dólares, muy inferior al de 1978. La recesión posterior llevó la producción a sólo $30 \mathrm{mi}-$ llones de dólares en 1991. En México, de un máximo de 96 millones de dólares en 1982, el valor de la producción se contrajo para llegar a ser de sólo 33 millones en 1987. 
En contraste con Argentina y México, Brasil ha tenido una industria relativamente poco abierta al comercio internacional, aunque ha habido modificaciones en años recientes. ${ }^{11} \mathrm{El}$ coeficiente de exportación de la producción brasileña fue inferior al 5\% en promedio en 1985-1989 y llegó al 14\% en 1990 . El coeficiente de importación aumentó de $10 \%$ en 1985-1986 a 44\% en 1990. En Argentina, el coeficiente de exportación en 1986-1990 fue del 55\% y el de importación del 63\%. En México las importaciones abastecen entre el 80 y el $90 \%$ del consumo aparente $\mathrm{y}$ las exportaciones han tenido una cierta envergadura.

\section{a) Características estructurales y tipo de empresas} Las pequeñas y medianas empresas dominan la producción de máquinas herramientas en Argentina, Brasil y México, aunque en el caso brasileño hay ciertas excepciones. A fines de los años ochenta, la empresa líder ocupaba 2000 personas y facturaba casi 100 millones de dólares. En contraste, la mayor empresa argentina sólo llegó a ocupar 320 empleados y a facturar 10 millones de dólares en 1988.

En tanto que la copia se ha utilizado intensamente en esta industria para absorber tecnología, la concesión de licencias de fabricación, las coinversiones y, en menor medida, la inversión extranjera directa (IED) han ganado creciente importancia. La IED ha sido significativa en Brasil, donde a partir de los años sesenta se establecieron varias empresas alemanas, acompañando el crecimiento de las filiales de empresas de vehículos automotores.

En una industria en la que los cambios tecnológicos son inherentes a su dinámica de crecimiento $\mathrm{y}$ despliegue internacional, desde mediados de los años setenta los avances tecnológicos se aceleraron como resultado de los progresos en la microelectrónica. $\mathrm{La}$ expresión más visible de esta tendencia fue la incorporación del control numérico $(\mathrm{CN})$. Esta innovación, que permitió introducir las ventajas de la automatización al hasta entonces vedado campo de las series de producción cortas, fue generada en los años cincuenta en los Estados Unidos. Con la introducción de las microcomputadoras en la unidad de control y su transformación en control numérico computarizado (CNC), a partir de 1975 se aceleró su difusión.

\footnotetext{
${ }^{11}$ La producción de esta industria es transable internacionalmente en grado alto y creciente. El coeficiente de exportaciones a nivel mundial pasó de $36 \%$ a $47 \%$ entre 1970 y 1990 . En este período, el coeficiente de abastecimiento importado en los propios países productores creció de $31 \%$ a $41 \%$.
}

Si bien ya se producían máquinas herramientas con control numérico en Brasil desde 1973, sólo en la segunda mitad de los años ochenta el volumen de producción de aquéllas con control numérico computarizado superó las mil unidades anuales. En 1989 las MHCNC significaban el $44 \%$ del valor de las ventas de máquinas herramientas por arranque de viruta. En el caso argentino, la producción local de MHCNC se inició en 1979 y, luego de varios años de escaso volumen (entre 8 y 13 unidades), en 1987 se llegó a 100 unidades (de las cuales se exportaron 77), que representaron un cuarto del valor total de la producción de máquinas herramientas. En México, aunque hay bastante difusión de MHCNC importadas, la producción nacional de ellas no ha alcanzado un volumen significativo. De todas formas, en los países en estudio la mayor parte del mercado en los años ochenta estuvo orientada hacia máquinas herramientas convencionales y la mayoría de las empresas estudiadas se especializa en su producción.

Las economías de escala han tenido poca incidencia en la fabricación de las máquinas herramientas convencionales, aunque han aumentado en la producción de MHCNC. En contraste, las economías de especialización son significativas en esta rama y no sólo caracterizan su producción final sino que son un rasgo distintivo de la desintegración vertical que suele tener esta industria en los países desarrollados.

En contraste con lo que ocurre en esos países, la manufactura de máquinas herramientas en Brasil exhibe un alto grado de integración nacional y vertical y una gran diversificación de la producción. Al mismo tiempo, por la política de reserva de mercado en informática que rige en el país desde 1982, se impulsó la fabricación interna de las unidades CNC, lo cual aumentó el grado de integración nacional, y en la empresa líder (que se autoabastecía de unidades $\mathrm{CNC}$ ) se elevó el grado de integración vertical de la producción. Aunque las plantas argentinas presentan menos integración vertical y diversificación que las brasileñas, se han visto perjudicadas por la falta de proveedores de partes y componentes y por sus escasas economías de especialización. Las plantas mexicanas, por su parte, tienen una producción bastante diversificada y, salvo excepciones, registran una escasa integración vertical debido al tipo y contenido nacional de las máquinas herramientas que fabrican.

b) Estrategias productivas y tecnológicas

A diferencia de lo sucedido en la petroquímica, en este sector se ha desplegado un abanico de estrategias 
empresariales, especialmente en Argentina y Brasil. La razón principal de esta diferencia entre los dos sectores se encuentra en la dinámica del cambio tecnológico, en los canales de acceso a él y en la mayor rigidez del proceso productivo y del marco regulatorio que exhibe la industria petroquímica. En la industria de máquinas herramientas, la incorporación de las MHCNC renovó productos y procesos, elevando al mismo tiempo las barreras a la entrada de las empresas que abordaron su producción con posterioridad. Sin embargo, las posibilidades de utilización de máquinas convencionales continúan siendo importantes. En este marco, las empresas tuvieron, desde el punto de vista técnico, un margen de decisión más amplio que sus pares petroquímicas entre distintas alternativas de producción.

Comparando las empresas estudiadas se ha construido una tipología que las clasifica en tres grupos. El primero está formado por empresas que han seguido una estrategia de liderazgo, alcanzando una cuota significativa del mercado y siendo pioneras en la introducción y fabricación en escala comercial de MHCNC. En el segundo grupo se incluyen aquellas empresas que, a pesar de haber asignado recursos a actualizar su tecnología de productos y de procesos, tienen un mayor rezago que las líderes respecto del nivel internacional, y se han lanzado más tarde a la producción de MHCNC. Las empresas que han seguido una estrategia de sobrevivencia más o menos pasiva constituyen el tercer grupo. ${ }^{12}$

El hecho de que tres de las empresas brasileñas que han seguido una estrategia de liderazgo contasen con insumos tecnológicos provistos por sus casas matrices o socios extranjeros pone de relieve la importancia que tiene esa fuente de acceso a la tecnología. La restante empresa brasileña de capital nacional en este grupo dio en 1986 un gran salto tecnológico en ingeniería de producto y de procesos, recurriendo a licencias del exterior. Un procedimiento similar utilizó una de las empresas argentinas en 1983 para obtener tecnología de producto. La otra empresa argentina, en cambio, es la única que ha seguido la estrategia de confiar en sus propias fuerzas, decisión estrictamente derivada de la visión particular de su dueño.

\footnotetext{
12 En el primer grupo se incluyen cuatro empresas brasileñas (de las cuales dos son filiales extranjeras, una es mixta y otra de capital nacional) y dos argentinas de capital nacional. El segundo grupo está formado por cinco empresas en Brasil (de las cuales una es extranjera) y tres en Argentina. El tercer grupo comprende a todas las empresas estudiadas en México, cuatro argentinas y cinco brasileñas.
}

En todos estos casos, además de haberse hecho fuertes inversiones en la segunda mitad de la década de 1980, se han destinado recursos significativos a la capacitación del personal en materia de producción y diseño. Sin embargo, los esfuerzos tecnológicos realizados por la empresa brasileña de capital nacional y por la argentina que ha hecho avances propios han sido mayores que los de sus competidores en ambos países.

El ciclo de reactivación del mercado brasileño a partir de 1984 constituyó un escenario favorable para la acción de estas empresas. Las argentinas también se beneficiaron de esta circunstancia debido al acuerdo de integración que empezó a regir para estos productos en 1986. La recesión posterior y el menor financiamiento disponible para las ventas llevó a estas empresas a paralizar la inversión y recortar personal, incluido el asignado a actividades tecnológicas. Una tendencia similar, aunque menos acentuada, se observa en las empresas brasileñas con estrategia de liderazgo.

Las empresas brasileñas que componen el segundo grupo (de tamaño mediano, excepto una que es pequeña) entraron a producir MHCNC entre 1985 y 1988. Los dos pequeños fabricantes argentinos de fresadoras convencionales incluidos en este grupo comenzaron a producir equipos con CNC entre 1986 y 1990, aunque en forma incipiente. También otra pequeña empresa argentina productora de prensas rápidas ha incorporado el automatismo a sus máquinas herramientas. Las empresas argentinas aludidas se distinguen por haber mejorado su tecnología de producto y de procesos y realizado inversiones destinadas a ampliar su capacidad a fines de los años ochenta.

Tres de las cuatro empresas de capital nacional que componen este grupo en Brasil intentaron obtener licencias para avanzar en la tecnología de MHCNC pero no tuvieron éxito en esa estrategia. Una empresa optó por el desarrollo propio y las otras dos intentaron una empresa mixta con un socio extranjero. En cambio, las empresas argentinas no recurrieron a licencias.

Una de las diferencias entre las empresas argentinas y brasileñas de este grupo es que las primeras no han alcanzado la producción de equipos con $\mathrm{CNC}$ en escala comercial significativa. Las empresas brasileñas, de todas maneras, sólo han vendido en el mercado interno. Otra diferencia importante es que las empresas brasileñas han logrado reducir costos por medio de innovaciones en los procesos, como células de fabricación, producción justo a tiempo e informa- 
tización. Estas innovaciones, que requieren relativamente poca inversión, se obtuvieron fundamentalmente a través de empresas locales de consultoría. Al igual que en las empresas del primer grupo, todas las de éste actualmente han reducido el personal vinculado a actividades tecnológicas y abandonado proyectos de productos.

El hecho de operar en mercados donde las ventajas de localización parecen ser importantes (por ejemplo, donde hay escuelas de enseñanza técnica, pequeños talleres o ingenios azucareros), el control que se ha ejercido desde 1987 sobre el aumento de los salarios y la necesidad (o compromiso vital) de los fabricantes son los factores que han facilitado la sobrevivencia de las empresas mexicanas. Los fabricantes de máquinas herramientas por deformación han sobrevivido modificando la gama de productos y reduciendo su contenido nacional (en el caso de las prensas). Los fabricantes de máquinas herramientas por arranque de viruta y de herramientas para máquinas herramientas han hecho algunas inversiones e incorporado MHCNC, sin modificar la gama de productos, pero reduciendo su contenido nacional y aumentando los servicios que ofrecen a los clientes.
Las cuatro empresas argentinas de este grupo han seguido una estrategia de sobrevivencia más activa que pasiva, tratando de mejorar la tecnología de producto. ${ }^{13}$ En general, registraron altos coeficientes de exportación en la segunda mitad de los años ochenta. Sin embargo, en ese período no hicieron inversiones para ampliar su capacidad ni modificaron la tecnología de procesos. Basan su competitividad en la especialización en máquinas convencionales y en la adaptación del producto a las necesidades específicas del usuario, sin considerar estos diseños - generalmente realizados por el dueño- en los costos de producción.

En Brasil fueron identificadas cuatro empresas de tamaño pequeño y mediano que siguieron una estrategia de sobrevivencia pasiva en los años ochenta. Producen para el mercado interno (ninguna exporta) en forma muy diversificada y con un alto grado de integración vertical. A partir de la contracción de los últimos años, todas estas empresas en los tres países redujeron personal. Por otra parte, su especialización en máquinas herramientas convencionales parece exponerlas menos que a las empresas de los otros grupos a los efectos de la apertura comercial.

\section{La configuración macroeconómica}

\section{y las políticas públicas}

La configuración de los factores estructurales que enmarcan las estrategias empresariales muestra significativas diferencias entre los dos sectores y considerables semejanzas entre las tres economías en el período analizado. La estructura de la producción y de la demanda, la dinámica del progreso técnico, las formas predominantes de internacionalización, las características de la empresa típica y la internalización de estos elementos en la regulación sectorial explican en buena medida los diferentes senderos sectoriales y su repetición en los tres casos nacionales. Las particularidades en cada país del marco regulatorio y de la evolución macroeconómica e institucional y, entrela-

13 Es importante tener en cuenta que en el estudio argentino se dejó de lado aquellos establecimientos que sobrevivieron en los años ochenta con los mismos productos y que hacían reparaciones o servicios de mecanizado para subsistir. zadamente, la historia empresarial y sectorial explican, a su vez, las diferencias encontradas dentro de un mismo sector entre los tres países.

\section{La crisis del Estado desarrollista}

La evolución de los años ochenta marca la crisis del Estado desarrollista en los tres países analizados. En más de cuarenta años de desarrollo industrial basado fundamentalmente en la sustitución de importaciones y el crecimiento del mercado interno, se erigió un Estado con fuerte presencia directa en el aparato productivo y con liderazgo en el proceso de inversión y acumulación de capital, que desplegó un enorme instrumental regulatorio en la promoción de actividades económicas y que conservó capacidad de arbitraje e intervención en el conflicto distributivo a través del sistema de precios y el presupuesto fiscal. Las prácti- 
cas sociales se configuraron siempre con referencia a esa decisiva capacidad de intervención.

Paralelamente, se instaló un aparato industrial bastante diversificado, incluyendo sectores de industria básica y de bienes de capital. Este proceso alcanzó su máxima expresión en Brasil a fines de los años setenta. En este marco, el desarrollo sustitutivo fue acumulando algunos desequilibrios que tendieron a expresarse principalmente como crisis periódicas en la balanza de pagos en México, como crisis inflacionarias en Brasil y como una combinación de ambas en Argentina. Las consecuencias de la fase de endeudamiento externo de mediados de los años setenta, sintetizadas en la instalación -a partir de 1981 — de una restricción fiscal y externa de carácter permanente estimada entre 5 y 10 puntos del PIB, implicaron el quiebre del modelo y de la eficacia de las instituciones desarrollistas.

Paradójicamente, la capacidad de las tres economías de asumir el ajuste externo consiguiente tuvo como un elemento esencial la maduración de los grandes proyectos de inversión en industria y energía desarrollados en la última etapa de la promoción sustitutiva. Estos, diseñados en función de las perspectivas de crecimiento del mercado interno estimadas en los años setenta, se redirigieron hacia los mercados externos. El proceso fue acompañado de fuertes devaluaciones que originaron marcados cambios en los precios relativos. La debilidad fiscal, en un contexto de mayor presión sobre el gasto y de estructuras de recaudación ineficientes y regresivas, llevó a un persistente proceso de desmonetización.

El cuadro fiscal no sólo debilitó la moneda sino que también comprimió la inversión pública y restringió las posibilidades de aplicar instrumentos directos de estímulo a las inversiones privadas. El régimen de alta inflación tendió a perpetuarse, mientras las políticas cambiarias y monetarias se hicieron cada vez más ineficaces. Los agentes económicos anticiparon esta crisis al dar prioridad a mecanismos de valorización financiera y otros comportamientos especulativos, depreciando aún más los ya escasos mecanismos de intervención estatal.

En cada uno de los tres países la crisis del Estado y la relación entre éste y las diversas fracciones sociales se procesó de modo diferente. En Argentina, la pauta de distribución del ingreso fue alterada radicalmente a partir de 1976, quebrando una dinámica de crecimiento extensivo del mercado interno. Paralelamente, la centralización de capital se aceleró con la constitución y consolidación de un número relativa- mente escaso de conglomerados económico-financieros que tenían en la relación preferente con el Estado una mayor capacidad de acumulación y apropiación de excedentes. Este proceso liquidó abruptamente una configuración social relativamente más equilibrada y debilitó el proyecto industrialista. El ajuste de los años ochenta operó sobre esta base, profundizando tendencias ya instaladas. Por otra parte, el proceso de hiperinflación sintetizó la quiebra del Estado y facilitó la adopción de un cambio profundo en la regulación económico-social.

En Brasil, en cambio, se ingresó al período de ajuste inmediatamente después de un masivo programa de inversiones, liderado por el Estado, que completó (literalmente) la matriz industrial del país, promovió un mejor balance energético, creó mayor capacidad de producción agropecuaria y generó nueva oferta exportable. En su apogeo (década de 1970) el crecimiento económico fue espectacular y la eventual resolución de los problemas de inequidad social estuvo asociada al sostenimiento permanente de ese ritmo expansivo. En estas condiciones, el ajuste fue considerado imprescindible para enfrentar el shock externo, pero necesariamente transitorio. La demanda social de crecimiento siguió siendo prioritaria - aún en relación con la estabilidad - y la industrialización siguió siendo considerada la vía más idónea para alcanzarlo.

El Estado mexicano no evitó la crisis, pero pudo realizar una mejor gestión macroeconómica del ajuste, favorecido por su carácter de propietario y exportador directo de elevados recursos petroleros. Junto con otras razones propias de la estructura político-social, esta circunstancia parece haberle otorgado un grado de autonomía relativa mayor, lo que explicaría también que haya podido aplicar las reformas estructurales más temprano que los otros dos países, venciendo las naturales resistencias internas. Por otra parte, el peso de la vinculación económica y política con los Estados Unidos parece haber sido también determinante para imponer en el marco de la crisis las recomendaciones del Consenso de Washington. Del mismo modo, las posteriores negociaciones en el marco del Tratado de Libre Comercio de América del Norte (NAFTA) contribuyeron a consolidar el programa de reformas.

Estas diferencias — que surgen de la matriz socioestatal de cada uno de los tres países- se plasman también en el debate respectivo y en las posiciones predominantes sobre política industrial. En el caso argentino, las prioridades de política económica se centraron finalmente en la consecución de la es- 
tabilidad de precios y en la total desregulación de los mercados, abandonando los criterios de intervención en los mecanismos mercantiles de asignación de recursos. En la práctica, la falta de selectividad tendió a acentuar el proceso de concentración económica. Si bien se declaró el compromiso ideológico del gran empresariado con el nuevo esquema de regulación que instalaron las reformas, aún no se ha reactivado la inversión en sectores de bienes transables en el exterior.

El predominio de la "cultura industrialista" y la persistencia de la demanda de mayor crecimiento han sido recogidos, en cierta medida, en el programa de ajuste estructural en Brasil. Esto se traduce en una mayor gradualidad y menor profundidad del proceso de apertura comercial, y en la formulación de políticas explícitas tanto de promoción del desarrollo tecnológico como de mejoramiento de la capacidad competitiva endógena de las empresas y de apoyo al desempeño exportador. De todas maneras, la falta de solución de los desequilibrios macroeconómicos debilita la capacidad de financiar esos instrumentos promocionales y torna incierta la trayectoria de la política industrial.

En el caso mexicano, el debate sobre política industrial está enmarcado en el proceso de constitución del NAFTA, el cual sobredetermina cualquier posible estrategia selectiva por parte del gobierno. Esto no ha significado, sin embargo, el paso a una configuración de políticas tan intensamente de mercado como en el caso argentino. $\mathrm{Al}$ menos tres hechos podrían señalarse para justificar esta afirmación: i) la presencia de elaborados mecanismos de negociación macroeconómica con empresarios y sindicatos; ii) la persistencia de algunos mecanismos regulatorios internos y de la propiedad estatal de ciertos recursos claves (por ejemplo, petróleo), y iii) las discusiones planteadas en la negociación del NAFTA, donde el gobierno mexicano mostró su intención de obtener un trato diferencial para determinados sectores considerados estratégicos.

\section{El impacto sobre las estrategias empresariales}

Dentro de este marco general, las diferencias en la jerarquía y coherencia de los instrumentos de política utilizados y en los resultados obtenidos cuentan en el momento de apreciar matices en las trayectorias sectoriales y en las estrategias empresariales. La crisis de las instituciones y de la regulación correspondiente a la etapa sustitutiva de importaciones se procesó en Argentina de un modo comparativamente más desestructurante y desarticulador de la actividad productiva. Dos fenómenos dan cuenta de esta diferencia que parece esencial en la evolución de nexo entre políticas públicas y estrategias privadas. Uno es el carácter mucho más recesivo —contracción más profunda y por tiempo más prolongado- del ajuste realizado en la primera fase. El otro es la virtual desaparición de un sistema formal de financiamiento y crédito. Una consecuencia importante de lo anterior fue el despliegue, en una etapa comparativamente más temprana y en forma más difundida, de estrategias empresariales defensivas y de racionalización.

Esta diferencia se mantiene al comparar la evolución de la fase de reformas estructurales. Es también en Argentina donde los mecanismos de liberalización, apertura y desregulación son adoptados de modo más drástico y general y aplicados sin gradualidad en un período muy corto de tiempo. Esto impacta sobre las estrategias de las empresas en un doble sentido. Por una parte, no hay tiempo para adaptarse progresivamente a las nuevas condiciones de competencia, que son implantadas de una vez y resultan abiertamente contradictorias con el aprendizaje histórico de las empresas. Por otra, se crea un ambiente de irreversibilidad que fuerza la toma rápida de decisiones de largo plazo. En este marco se generan iniciativas de asociación con operadores internacionales, entre los que quieren permanecer, o bien de venta de los activos y salida del negocio. Hay algunos indicios de esta trayectoria en buena parte de la industria argentina, incluida la petroquímica, y parece ser la más probable en algunas empresas de máquinas herramientas en las que pesa menos la tradición familiar.

Es evidente también que en los tres países la preocupación por el alcance de los equilibrios macroeconómicos, en un contexto de creciente restricción del financiamiento de los déficit externo y fiscal, sobredeterminó el diseño y ejecución de la política industrial. Por esta razón, por una mayor atención a sus vicios anteriores y por la generalización y predominio de recomendaciones de liberalización, las políticas sectoriales se vieron crecientemente debilitadas. Sin embargo, aquí también aparecen diferencias significativas. Más allá de la progresiva dificultad de financiamiento, en Brasil, tanto en la fase de ajuste como en la de reformas estructurales, la preocupación por establecer instrumentos de promoción y orientación de las inversiones y exportaciones de manufacturas siguió estando presente. 
Esta atención mayor en el caso brasileño a las políticas macroeconómicas más expansivas y a algunos elementos de política industrial se manifiesta, por un lado, en momentos de expansión del crecimiento del sector durante el período de ajuste y, por otro, en el carácter relativamente más proteccionista de las reformas al régimen de comercio. Se manifiesta también en una ponderación comparativamente más significativa de las iniciativas de inversión y de ampliación de capacidad dentro de las estrategias empresariales. Parece haber en Brasil un fuerte componente de inercia - una especie de cultura de crecimientoque impacta tanto las políticas públicas como las decisiones de las empresas, y que en la actualidad se traduce en un fuerte debate sobre la real sustentabilidad del ajuste y de las reformas en ausencia de una reactivación prolongada. Paralelamente, son menos intensas las demandas de estabilización y más fuerte la preocupación por definir una orientación estratégica de largo plazo.

Hemos tratado de subrayar que la propia historia de la empresa condiciona el proceso de decisión empresarial. Pero también la historia pesa en la interpretación que las empresas hacen de las señales macroeconómicas y de las políticas públicas. En este sentido, para la adopción de estrategias de largo plazo por parte de las empresas es clave un horizonte previsible respecto al desempeño de las variables económicas y la consolidación de señales de la configuración productiva a largo plazo. En la interacción virtuosa de la consistencia de las políticas públicas, la credibilidad de su permanencia y la adaptación de las prácticas empresariales a los requerimientos de inversión que aquéllas plantean parece residir la sustentabilidad de cualquier programa de reformas. La oportunidad y secuencia de políticas y estrategias es, para ello, de suma importancia.

La experiencia de México puede servir para ilustrar esta circunstancia. En sus aspectos básicos y de mayor ruptura con el esquema anterior, el programa de reformas al régimen comercial mexicano estaba ya

\section{V}

\section{Conclusiones}

Las políticas de protección y asistencia estatal alentaron la instalación y desarrollo de un fuerte parque industrial en Argentina, Brasil y México. Los már- en vigor a fines de 1988. Al mismo tiempo, los éxitos del plan antiinflacionario también tendían a consolidarse, aunque eran todavía inciertos los términos probables de la renegociación a largo plazo con los acreedores externos. Por otra parte, comenzaba la negociación de un acuerdo de libre comercio con Estados Unidos que, de concretarse, tendría un fuerte impacto en la reestructuración productiva, cuya forma y magnitud dependían también de las condiciones del acuerdo. En otros términos, instaladas condiciones de estabilidad que contrastaban con la volatilidad de los precios relativos de los últimos años, y estando en marcha la liberalización comercial, permanecían serias incertidumbres acerca del escenario financiero y productivo en el largo plazo.

La respuesta inicial de las empresas en ese contexto dio prioridad a los componentes defensivos y de racionalización, dejando de lado iniciativas tecnológicas y de inversión y centrando su estrategia en movimientos comerciales y de recomposición financiera y patrimonial. Sólo en 1992, luego de más de tres años de relativa estabilidad de los precios internos, de dos años de ingreso al Plan Brady y, fundamentalmente, estando muy adelantadas las negociaciones en el NAFTA, pareció reactivarse el proceso de inversión. De todas maneras, siguen ausentes estrategias más activas en materia tecnológica.

De la observación del caso mexicano se puede recoger algunas lecciones. Por un lado, es necesario tomar en cuenta el rezago que se da entre la aplicación de las reformas y la redefinición de las estrategias privadas $y$, en especial, la importancia de un escenario de certidumbre a largo plazo para orientar las decisiones empresariales. Por otro, la demora de las empresas en reactivar el proceso de inversión puede afectar los equilibrios de los sectores fiscal y externo, y tornarlos precarios, realimentando incertidumbres. Equilibrar ambas cosas parece ser el principal problema de política económica en el actual escenario de economía abierta de Argentina, Brasil y México. genes excesivos de protección y la redundancia de algunos incentivos promocionales permitieron que las empresas operasen con costos altos y acumularan

INDUSTRIAS PETROQUIMICA Y DE MAQUINAS HERRAMIENTAS: ESTRATEGIAS EMPRESARIALES - D. CHUDNOVSKY, A. LOPEZ Y F. PORTA 
ganancias extraordinarias. El poder de mercado de las empresas y la progresiva consolidación de regímenes de alta inflación posibilitaron el traslado a los precios de esos mayores costos e inhibieron una mejor distribución de los beneficios propios de la maduración de los proyectos a los consumidores finales o intermedios.

Estos rasgos caracterizaron el desarrollo de las industrias petroquímica y de máquinas herramientas en los tres países, en particular durante la década de 1980. Fueron más acentuados en la petroquímica, ya que a la existencia de programas específicos de promoción sectorial se sumó una configuración de mercados oligopólicos y empresas de gran tamaño. En la industria de máquinas herramientas, en cambio, se atenuaron porque los instrumentos promocionales fueron más débiles, la protección era perforada por mecanismos de desgravación para la importación de equipos, y las pequeñas y medianas empresas predominantes disfrutaban de un menor poder de mercado.

La maduración de las empresas, en lo tecnológico-productivo, estuvo vinculada a la expansión de su capacidad de producción y a las perspectivas de ampliar la demanda. Las empresas petroquímicas estudiadas invirtieron en plantas a escala internacional y con las tecnologías más modernas del momento en los años 1970 y 1980 , como consecuencia de fuertes incentivos gubernamentales. Las empresas brasileñas y argentinas de máquinas herramientas que en los años ochenta ingresaron a la producción de $\mathrm{MHCNC}$, impulsadas por la emergencia de un nuevo patrón tecnológico, fundaron sus estrategias de liderazgo en un escenario previsible de ampliación del mercado nacional o regional.

En la petroquímica, descartada la posibilidad de alcanzar el umbral de gastos en investigación y desarrollo necesario para generar innovaciones mayores en procesos y productos, las empresas realizaron exitosamente actividades de optimización de procesos y adecuado manejo de planta que maximizaron su rentabilidad operativa. En Brasil y México algunas empresas proyectaron elaborar especialidades más complejas. El margen para decisiones en el campo tecnoproductivo fue más amplio en la industria de máquinas herramientas. Algunas empresas avanzaron hacia la producción de MHCNC - generalmente apoyadas por socios o licenciantes extranjeros- con algún retraso respecto de las principales empresas y países productores. Otras, en cambio, por razones de tamaño, por aversión al riesgo o por especializarse en productos menos dinámicos, evolucionaron dentro de una modalidad vegetativa.

La economía cerrada no fue obstáculo para que algunas empresas - frente a perspectivas específicas de expansión o de reserva de mercado- desarrollaran actividades y esfuerzos tecnológicos dentro del sendero posible definido por las condiciones estructurales y el patrón de internacionalización de cada sector. Sin embargo, la mayor productividad no se trasladó a los precios. La falta de acicates o presiones para que, al madurar los proyectos y las capacidades manufactureras, los beneficios se trasladaran en mayor medida a los usuarios, fue una falla importante de la-política industrial de los años setenta y ochenta.

La combinación - con grados diversos en cada país- de una coyuntura internacional adversa, problemas macroeconómicos y reformas estructurales interrumpió la trayectoria expansiva de las empresas. En el nuevo escenario, la reacción predominante en las empresas fue la de racionalizar y cortar gastos, eliminando una "gordura" acumulada que ya no podía incorporarse fácilmente a los precios, y posicionarse en productos maduros, debilitando o abandonando proyectos de ampliación de capacidad y de mejoramiento tecnológico. La mayor exposición a la competencia derivada del nuevo cuadro macroeconómico y de políticas públicas obligó a una baja relativa de precios en el mercado interno, pero no ha estimulado - sino más bien al contrario - una mayor agresividad productiva y tecnológica.

En el escenario de economía abierta, las empresas petroquímicas que habían proyectado moverse hacia productos más complejos desistieron del intento, y las empresas productoras de máquinas herramientas que avanzaron dentro del nuevo paradigma del CNC encuentran grandes dificultades para sostener su producción. Por otra parte, a excepción del sector de máquinas herramientas en México, los casos analizados responden a industrias firmemente establecidas, con una historia prolongada y con capacidades empresariales, fabriles y tecnológicas ya desarrolladas. Parece natural que entre las primeras reacciones de las empresas no se cuente el abandono de la actividad o su transformación en importadores.

Afectada la trayectoria evolutiva de las empresas, éstas se refugian en productos maduros y nichos protegidos por ventajas de localización. El escenario de mayor competencia generado por las reformas no despierta ni descubre el espíritu realizador de los productores, pero tampoco los desaloja inmediatamente de la actividad. Las empresas apuestan a sobrevivir, 
reduciendo estructuras y, en algunos casos, incorporando socios extranjeros. Podría argumentarse que el escaso tiempo transcurrido no permite verificar la hipótesis "eficientista" ni la "desindustrialista". Vale la pena especular sobre estas posibilidades.

Por una parte, las empresas responden a la nueva situación con decisiones influidas por su historia previa; en condiciones de incertidumbre sobre las tendencias de la evolución del mercado nacional e internacional, y sin los beneficios potenciales de un marco regulatorio promocional, las empresas privilegian acciones defensivas. Por otra, sus respuestas en el corto plazo influyen en sus posibilidades de acción futuras. En este sentido, el paso del tiempo no es inocuo, como parece sugerir el argumento "eficientista".

En la industria petroquímica, el fuerte recorte del personal asignado a tareas no rutinarias no sólo ha reducido el techo de las aspiraciones tecnológicas de las empresas locales, sino que también ha debilitado su capacidad de negociación con los proveedores internacionales. En esas condiciones, la racionalización en curso claramente está afectando decisiones futuras que hacen a la eventual expansión de la capacidad física y tecnológica. Sin embargo, para permanecer con posibilidades en el mercado, algunas empresas deben integrarse verticalmente, lo que hacen favorecidas por las medidas de privatización y desregulación en marcha. De este modo, por una parte, pueden alcanzar una dimensión más competitiva y, por otra, están en condiciones de gestionar acuerdos privados de ordenamiento de los mercados y reducir el alcance de las externalidades asociadas a la mayor competencia.

En la industria de máquinas herramientas, la cancelación de los planes de inversión y la abrupta reducción del personal calificado - que constituye el activo más preciado en esta actividad- sugieren que los intentos de mantenerse o, eventualmente, expandirse en los segmentos tecnológicamente más avanzados se verán seriamente comprometidos. La adquisición de una empresa líder en Argentina por parte de una gran firma italiana y la dificultad cada vez mayor de acceso a esta tecnología sin socios externos son indicios de menores grados de libertad para el avance de las empresas locales, más allá de aquellos segmentos del mercado en los que las ventajas de localización sean significativas.

Estas tendencias se dibujan con mayor nitidez en el caso mexicano, donde es mayor el tiempo transcurrido desde la adopción de las reformas. La discusión previa en torno a los factores estructurales que determinan las decisiones de las empresas sugiere que las estrategias desplegadas actualmente por las empresas en México podrían verse reflejadas en el mediano plazo en las industrias argentina y brasileña. Cambios en el entorno macroeconómico y de políticas públicas sin duda podrían generar escenarios diferentes. En este sentido, en razón de su historia de desarrollo industrial y de las peculiaridades del Estado y su clase empresarial, es probable que en Brasil emerja un panorama más dinámico y complejo.

\section{Bibliografia}

APLA (Asociación Petroquímica Latinoamericana) (1988): Argentina-Brasil. Comercio bilateral petroquímico 1980-1987, Buenos Aires.

(1991): La industria petroquímica ante la integración Argentina-Brasil, Buenos Aires.

BID (Banco Interamericano de Desarrollo) (1991): Progreso económico y social en América Latina. Informe 1991, Washington D. C., octubre.

Clemente de Oliveira, J. (1990): Desenvolvimento tecnológico da indústria e a constituicão de um sistema nacional de inovacão no Brasil - $O$ setor petroquímico-, Campinas, Brasil, Universidade Estadual de Campinas (UNICAMP).

Chudnovsky, D., A. López y F. Porta (1992): Ajuste estructural y estrategias empresariales en la Argentina. Un estudio de los sectores petroquímico y de máquinas herramientas, Documento de trabajo, $\mathrm{N}^{\circ} 10$, Buenos Aires, Centro de Investigaciones para la Transformación (CENIT).

(1993): Ajuste estructural y estrategias empresariales en Argentina, Brasil y México. Un análisis comparativo de la industria petroquímica y de máquinas herramientas, Documento de trabajo, $\mathrm{N}^{\circ} 11$, Buenos Aires, CENIT.
Dosi, G. y otros (eds.) (1988): Technical Change and Economic Theory, Londres, Pinter Publishers.

Erber, F. y R. Vermulm (1992): Ajuste estrutural e estratégias empresariais- Um estudo dos setores petroquímico e de máquinas ferramenta no Brasil, Rio de Janeiro, Instituto de Planificación Económica y Social (IPEA).

Frichstak, C., B. Hadjimichael y U. Zachau (1990): Competition Policies for Industrializing Countries, Washington, D. C., Banco Mundial.

Gutiérrez R., R. (1991): Desarrollo y consolidación de la industria petroquímica mexicana, Comercio exterior, vol 41 , No 4 , México, D.F., Banco Nacional de Comercio Exterior, S.N.C., abril.

Nelson, R. y S. Winter (1982): An Evolutionary Theory of Economic Change, Cambridge, Massachusetts, The Belknap Press, of Harvard University Press.

Unger, K., L. C. Saldaña, J. Jasso, y G. Durand (1992): Ajuste estructural y estrategias empresariales en las industrias petroquímica y de máquinas herramientas de México, México D.F., mimeo. 